\title{
HUBUNGAN ANTARA PENGETAHUAN IBU HAMIL TENTANG TANDA BAHAYA KEHAMILAN DENGAN KEPATUHAN KUNJUNGAN KEHAMILAN DI PUSKESMAS BANJAR SERASAN KOTA PONTIANAK TAHUN 2019
}

\author{
Katarina Iit ${ }^{1}$, Megalina Limoy ${ }^{2}$ \\ Akademi Kebidanan Panca Bhakti Pontianak \\ Email korespondensi: katarinaiit17@gmail.com
}

\begin{abstract}
Abstrak
Tanda-tanda bahaya kehamilan adalah tanda-tanda yang menunjukkan bahaya yang dapat terjadi selama kehamilan atau periode antenatal, yang jika tidak dilaporkan atau tidak terdeteksi dapat menyebabkan kematian ibu. Di wilayah kerja Pusat Kesehatan Masyarakat Banjar Serasan pada tahun 2019, ditemukan bahwa ada 11 wanita hamil dengan 11 tanda bahaya kehamilan dari Januari hingga Februari. Tujuan dari penelitian ini adalah untuk mengetahui hubungan antara pengetahuan ibu hamil tentang tanda-tanda bahaya kehamilan dengan kepatuhan terhadap kunjungan kehamilan di Pusat Kesehatan Masyarakat Banjar Serasan di Pontianak pada tahun 2019. Desain penelitian ini menggunakan korelasi deskriptif dengan pendekatan cross sectional. . Populasi adalah wanita hamil yang mengunjungi Puskesmas Banjar Serasan pada bulan Januari dan Februari 2019 dengan sampel sebanyak 50 orang. Instrumen dalam penelitian ini menggunakan kuesioner dan observasi, analisis data menggunakan analisis univariat dan bivariat. Hasil penelitian menunjukkan bahwa sebagian besar responden memiliki pengetahuan kurang sebanyak 30 responden (60\%) dan ada 9 responden (18\%) memiliki pengetahuan yang cukup tentang tanda-tanda bahaya kehamilan. Hasil kepatuhan dalam kunjungan kehamilan menunjukkan bahwa sebagian besar responden sebanyak 35 responden $(70 \%)$ tidak patuh dalam melakukan kunjungan kehamilan sesuai standar. Hasil analisis bivariat menunjukkan bahwa X2 hitung $(37,47)>$ X2 tabel $(5,991)$ yang berarti ada hubungan antara Pengetahuan Bahaya Kehamilan dan Kepatuhan Kunjungan Kehamilan di Puskesmas Banjar Serasan Pontianak pada tahun 2019. Saran bagi petugas kesehatan untuk memberikan informasi tentang tanda-tanda bahaya kehamilan.
\end{abstract}

Kata Kunci: Pengetahuan, Kepatuhan, Tanda Bahaya Kehamilan

\begin{abstract}
Pregnancy danger signs are signs that indicate a danger that can occur during pregnancy or the antenatal period, which if not reported or not detected can cause maternal death. In the working area of the Banjar Serasan Community Health Center in 2019, it was found that there were 11 pregnant women with 11 pregnancy danger signs from January to February. The purpose of this study was to determine the relationship between knowledge of pregnant women about the danger signs of pregnancy with compliance to pregnancy visits at the Banjar Serasan Community Health Center in Pontianak in 2019. The design of this study used descriptive correlations with cross sectional approaches. The population are pregnant women who visit the Banjar Serasan Community Health Center in January and February 2019 with a sample as many as 50 people. The instruments in this study used questionnaires and observations, data analysis used univariate and bivariate analyzes. The results shows that most of the respondents have lack of knowledge as many as 30 respondents $(60 \%)$ and there is 9 respondents $(18 \%)$ have sufficient knowledge about the danger signs of pregnancy. The results of compliance in pregnancy visits shows that most of respondents as many as 35 respondents (70\%) are not compliant in conducting pregnancy visits according to standards. Results of bivariate analize shows that X2 count (37.47) > X2 table (5.991) which means there is a relationship between Knowledge of Pregnancy Hazards and Pregnancy Visit Compliance at the Banjar Serasan Community Health Center in Pontianak in 2019. Suggestions for health workers to provide information about pregnancy danger signs.
\end{abstract}

Keywords: Knowledge, Compliance, Pregnancy Danger Signs

\section{Pendahuluan}

Kehamilan merupakan proses yang pada wanita hamil bersifat fisiologis, bukan alamiah dan normal. Perubahan yang terjadi patologis. Walau tidak dipungkiri dalam

\footnotetext{
${ }^{1}$ Dosen Akademi Kebidanan Panca Bhakti Pontianak 2 Dosen Akademi-Kebidanan Panca Bhakti-Pontianak
} 
beberapa kasus mungkin dapat terjadi komplikasi sejak awal karena kondisi tertentu atau komplikasi tersebut terjadi kemudian. Ibu hamil juga perlu merasakan adanya tanda-tanda bahaya kehamilan. Apabila tanda-tanda bahaya dalam kehamilan ini tidak dilaporkan atau terdeteksi, dapat mengancam jiwanya (Marmi, 2011).

Laporan Survey Demografi dan Kesehatan Indonesia (SDKI) tahun 2017 menyajikan tentang gangguan atau komplikasi kehamilan yang dialami oleh wanita 15-49 tahun yang memiliki kelahiran hidup terakhir dalam 5 tahun sebelum survey. 8 dari 10 (81\%) wanita tidak mengalami selama hamil. Diantara wanita yang mengalami komplikasi kehamilan, 5\% mengalami perdarahan berlebihan, masingmasing 3\% mengalami muntah terus-menerus dan bengkak kaki, tangan dan wajah atau sakit kepala yang disertai dengan kejang, serta masing-masing $2 \%$ mengalami mulas sebelum 9 bulan dan ketuban pecah dini. $8 \%$ wanita mengalami keluhan kehamilan lainnya, diantaranya demam tinggi, kejang dan pingsan, anemia serta hipertensi (SDKI, 2017).

Faktor utama penyebab kematian ibu melahirkan yakni perdarahan 30,13\%, hipertensi saat hamil, atau pre eklampsia $27,1 \%$ dan infeksi $7,3 \%$. Perdarahan menempati presentasi tertinggi yakni $30,13 \%$ anemia dan Kekurangan Energi Kronis (KEK) pada ibu hamil menjadi penyebab utama terjadinya perdarahan dan infeksi yang merupakan faktor kematian utama ibu (Kemenkes RI, 2016).

Berdasarkan dari sensus penduduk tahun 2010, angka kematian Ibu di Provinsi
Kalimantan Barat adalah sebesar 240 per 100.000 kelahiran hidup, sedangkan untuk nasional sebesar 259 per 100.000 kelahiran hidup. Hal ini berarti bahwa angka kematian ibu di Kalimantan Barat telah menunjukkan adanya penurunan yang sangat signifikan, dimana dalam dua dasawarsa, pada tahun 2012 angka kematian ibu di Kalimantan Barat berada dibawah angka nasional, baik dibandingkan dengan hasil SDKI maupun hasil sensus penduduk. Sedangkan, jika dilihat berdasarkan kasus kematian maternal yang terjadi pada tahun 2017 di Provinsi Kalimantan Barat, tercatat 98 kasus kematian ibu sehingga jika dihitung angka kematian ibu maternal dengan jumlah kelahiran hidup sebanyak 86.672, maka kematian ibu maternal di Provinsi Kalimantan Barat pada tahun 2016 adalah sebesar 133 per 100.000 kelahiran hidup. Kasus kematian ibu maternal terbesar ada di kabupaten Sanggau, yaitu sebesar 15 ibu maternal dan terkecil ada di kabupaten Kapuas Hulu, yaitu sebesar 2 ibu maternal, sedangkan di Kabupaten Pontianak sebesar 7 ibu maternal (Profil Kesehatan KalBar, 2017).

Angka Kematian Ibu (AKI) di Kabupaten Kubu Raya pada tahun 2016 naik dibandingkan pada tahun 2015. Hal tersebut ditandai dengan meningkatnya angka kematian ibu, jika pada tahun 2016 sebesar 97,65 per 100.000 kelahiran hidup yaitu sejumlah 12 kasus, sedangkan pada tahun 2015 sebanyak 87,5 per 100.000 kelahiran hidup. Hasil Audit Maternal Perinatal (AMP) menyimpulkan bahwa penyebab kematian ibu pada tahun 2016 adalah Pre Eklampsia Berat (PEB) sebanyak 33\% (4 
kasus), Perdarahan sebesar 17\% (2 kasus), Gagal jantung 17\% (2 kasus), Sepsis $17 \%$ (2 kasus) dan Lainnya $16 \%$ (2 kasus). Sedangkan pada 2017 angka kematian ibu yaitu 11 kasus (Profil Kesehatan Kabupaten Kubu Raya 2018). Masalah-masalah tersebut merupakan kasus dari adanya tanda bahaya kehamilan.

Cakupan kunjungan ibu hamil K1 pada tahun tahun 2018 dilaporkan mencapai 87,9\% dibawah target K1 95\%. Untuk cakupan kunjungan kehamilan K4 dilaporkan 71,5\% dibawah target $95 \%$. Sedangkan yang dikatakan patuh dalam melakukan kunjungan kehamilan hanya 50\% dari jumlah kunjungan. Jumlah kunjungan kehamilan 2019 pada bulan Januari dan februari berjumlah 100 orang, dan yang dikatakan patuh dalam melakukan kunjungan kehamilan hanya 40 orang (40\%).

\section{Metode}

Penelitian ini menggunakan penelitian survey yang bersifat deskriptif kolerasi dengan pendekatan cross sectional. Pada penelitian ini peneliti ingin mengetahui hubungan antara pengetahuan ibu hamil tentang tanda bahaya kehamilan dengan kepatuhan kunjungan kehamilan di Puskesmas Banjar Serasan Kota Pontianak tahun 2019. Teknik pengambilan sampel dengan convenience sampling atau sampling aksidental dengan jumlah sampel 50 ibu hamil.

\section{Hasil dan Pembahasan}

Tabel 1. Distribusi Frekuensi Berdasarkan Pengetahuan Ibu Hamil Tentang Tanda Bahaya Kehamilan di Puskesmas Banjar Serasan Kota Pontianak Tahun 2019

\begin{tabular}{ccc}
\hline \multirow{2}{*}{ Pengetahuan Responden } & \multicolumn{2}{c}{ Jumlah } \\
\cline { 2 - 3 } & $\mathrm{N}$ & $\%$ \\
\hline Baik & 11 & 22,0 \\
Cukup & 9 & 18,0 \\
Kurang & 30 & 60,0 \\
\hline
\end{tabular}

Berdasarkan tabel 4.1 diketahui bahwa sebagian besar dari responden yaitu 30 responden $(60 \%)$ berpengetahuan kurang dan sangat sedikit dari responden yaitu 9 responden (18\%) berpengetahuan cukup dalam pengetahuan tentang tanda bahaya kehamilan.

Tabel 2. Distribusi Frekuensi Berdasarkan Kepatuhan Kunjungan Kehamilan Di Puskesmas Banjar Serasan Kota Pontianak Tahun 2019

\begin{tabular}{ccc}
\hline Kepatuhan & \multicolumn{2}{c}{ Jumlah } \\
\cline { 2 - 3 } & $\mathrm{N}$ & $\%$ \\
\hline Tidak Patuh & 15 & 30,0 \\
Patuh & 35 & 70,0 \\
\hline
\end{tabular}

Tabel 2 diatas menunjukkan bahwa sebagian besar dari responden yaitu 35 responden $(70 \%)$ tidak patuh dalam melakukan kunjungan kehamilan sesuai standar. 
Tabel 3. Hubungan antara pengetahuan ibu hamil tentang tandabahaya kehamilan dengan kepatuhan kunjungan kehamilan

\begin{tabular}{ccccccccc}
\hline \multirow{3}{*}{ Pengetahuan } & \multicolumn{9}{c}{ Kepatuhan } & \multirow{2}{*}{ Total } & $\%$ & X hitung & X Tabel \\
\cline { 2 - 6 } & Patuh & $\%$ & $\begin{array}{c}\text { Tidak } \\
\text { Patuh }\end{array}$ & $\%$ & & & \\
\hline Baik & 11 & 22,0 & 0 & 0 & 11 & 22,0 & & \\
Cukup & 2 & 4,0 & 7 & 14,0 & 9 & 18,0 & 37,47 & 5,991 \\
Kurang & 2 & 4,0 & 28 & 56,0 & 30 & 60,0 & & \\
\hline
\end{tabular}

Berdasarkan dari tabel 3 diperoleh sebagian kecil dari responden yang memiliki pengetahuan baik dan patuh yaitu 11 responden (22\%), tidak patuh 0 respoden, dan sangat sedikit dari responden yang memiliki pengetahuan kurang dan patuh yaitu 2 responden $(4 \%)$ dan yang tidak patuh 28 responden $(56 \%)$.

Berdasarkan perhitungan dengan rumus chi kuadrat didapatkan nilai hitung $X^{2}$ hitung sebesar 37,47 sedangkan nilai pada tabel chi square $\mathrm{Db} 2$ dengan tingkat kepercayaan 95\% dan tingkat kesalahan 5\%. Pada penelitian ini $X^{2}$ hitung $(37,47) \geq \mathrm{x}$ tabel $(5,991)$ yang artinya Ha diterima dan Ho ditolak artinya Ada Hubungan antara pengetahuan ibu hamil tentang tanda bahaya kehamilan dengan kepatuhan kunjungan kehamilan.

\section{Pengetahuan Ibu Hamil Tentang Tanda Bahaya Kehamilan}

Berdasarkan tabel 1 diketahui bahwa sebagian besar dari responden yaitu 30 responden $(60 \%)$ berpengetahuan kurang dan sangat sedikit dari responden yaitu 9 responden (18\%) berpengetahuan cukup dalam pengetahuan tentang tanda bahaya kehamilan.

Hal ini menunjukkan bahwa sebagian besar dari responden memiliki pengetahuan yang kurang dalam melakukan kunjungan kehamilan sesuai standar, penyebabnya dari berbagai faktor yaitu rasa ingin tahu manfaat dari mengetahui tentang tanda bahaya kehamilan dengan bertanya kepada petugas kesehatan. Melalui media massa, serta informasi dari teman, tetangga, serta keluarga yang mengetahui manfaat mengetahui tentang tanda bahaya kehamilan.

Informasi dari petugas pelayanan kesehatan melalui pendidikan kesehatan ataupun konseling pada saat pelayanan kehamilan memberikan informasi penting melakukan kunjungan kehamilan sesuai standar. Namun, sangat sedikit dari responden yang berpengetahuan cukup, karena kurang peduli untuk melakukan kunjungan kehamilan, dan beranggapan bahwa itu merupakan hal yang tidak terlalu penting untuk dilakukan. Namun, sebagian kecil dari responden yang berpengetahuan baik, merupakan mampu mengetahui, mengaplikasikan, mengenai tanda bahaya kehamilan, ini dikarenakan oleh rasa kepedulian pada kehamilannya.

Penelitian yang dilakukan degan hasil dari seluruh responden yang telah diberikan kuesioner dalam bentuk pertanyaan, responden yang banyak menjawab salah yaitu Salah satu penyebab yang membuat ibu mengalami demam tinggi saat hamil yaitu psing padahal salah satu penyebabnya yaitu perdarahan. Ini 
akibat kurangnya pengetahuan ibu hamil tentang tanda bahaya kehamilan.

Begitu juga dengan hasil dari responden yang paling banyak di jawab benar oleh responden yaitu ukuran tekanan darah yang merupakan bahaya bagi ibu hamil yaitu 140/90 mmHg. Hal ini merupakan yang paling sering didengar dan dibicarakan sehingga responden mudah ingat ukuran tekanan darah yang merupakan bahaya bagi ibu hamil. sehingga dapat membuat responden merasa cemas harus mengetahui tanda bahaya kehamilan.

Hal ini sesuai dengan teori Notoatmodjo (2010) pengetahuan adalah hasil penginderaan manusia, atau hasil tahu seseorang terhadap objek melalui indera yang dimilikinya (mata, hidung, telinga, dan sebagainya). Dengan sendirinya, pada waktu penginderaan sampai menghasilkan pengetahuan tersebut sangat dipengaruhi oleh intesitas perhatian dan persepsi terhadap objek. Sebagian besar pengetahuan seseorang diperoleh melalui indera pendengaran (telinga), indera penglihatan (mata). Pengetahuan seseorang terhadap objek mempunyai intesitas atau tingkat yang berbeda-beda.

Tanda bahaya kehamilan adalah tandatanda yang mengindikasikan adanya bahaya yang bisa terjadi selama kehamilan atau periode antenatal, yang apabila tidak dilaporkan atau tidak terdeteksi bisa menyebabkan kematian ibu (Asrinah dkk, 2010).

Sangat penting ibu hamil mengetahui tentang tanda-tanda bahaya kehamilan agar bisa mendeteksi secara dini adanya tanda-tanda bahaya kehamilan dengan secara rutin melakukan pemeriksaan kehamilan ke tenaga kesehatan.

Menurut hasil penelitian yang dilakukan oleh Herlinawati tentang "Hubungan Antara Pengetahuan Ibu Hamil Tentang Kehamilan Resiko Tinggi Dengan Kunjungan Antenatal Care Di Puskesmas Sungan Durian Kabupaten Kubu Raya Tahun 2017”, Bahwa diketahui sebagian besar dari responden $(63,33 \%)$ berpengetahuan baik yaitu 19 orang.

Sedangkan penelitian yang dilakukan oleh Fitriana dengan judul "Hubungan Tingkat Pengetahuan Ibu Hamil Trimester III Tentang Tanda Bahaya Kehamilan Dengan kepatuhan Melakukan ANC Di BPS Sri Martuti Piyungan" Tahun 2011, bahwa ibu hamil di BPS Sri Martuti Piyungan sebagian besar memiliki pengetahuan tentang tanda bahaya kehamilan tinggi $(51,6 \%)$ dengan tingkat pendidikan sebagian besar SLTA $(61,3)$, melaksanakan kunjungan ANC secara patuh $(77,4 \%)$.

Hasil penelitian yang dilakukan oleh peneliti didapatkan pengetahuan sebagian besar dari responden yaitu 30 responden (60\%) berpengetahuan kurang dan sangat sedikit dari responden yaitu 9 responden berpengetahuan cukup dalam pengetahuan tentang tanda bahaya kehamilan. Kurangnya pengetahuan ibu hamil tentang tanda bahaya kehamilan karena ketidaktahuan tentang melakukan standar kunjungan kehamilan.

\section{Kepatuhan Kunjungan Kehamilan}

Berdasarkan tabel 2 diketahui bahwa sebagian besar dari responden yaitu 35 responden (70\%) tidak patuh dalam melakukan kunjungan kehamilan sesuai standar, dan 
sebagian kecil dari responden yaitu 15 responden (30\%) patuh dalam kunjungan kehamilan sesuai standar.

Kepatuhan tersebut ditunjukkan dari kesadaran ibu hamil tentang pentingnya melakukan kunjungan kehamilan sesuai dengan standar. Kepatuhan yang mendukung penelitian ini di tunjukkan responden dengan pernyataan patuh dan tidak patuh dalam melakukan kunjungan kehamilan sesuai standar.

Hal ini sesuai dengan teori Susanti (2013) kepatuhan melakukan kunjungan kehamilan didefinisikan perilaku ibu hamil yang mentaati semua anjuran oleh petugas kesehatan dalam melakukan kunjungan kehamilan. Kepatuhan kunjungan kehamilan diperoleh melalui perhitungan kunjungan kehamilan. Ibu hamil dikategorikan patuh apabila ibu hamil melakukan kunjungan kehamilan minimal 1 kali pada trimester I, 1 kali pada trimester II dan 2 kali pada trimester III sebaliknya ibu hamil dikatakan tidak patuh apabila ibu tidak melakukan kunjungan kehamilan minimal 1 kali pada trimester I (0 sampai 12 minggu), 1 kali pada trimester II (13 sampai 28 minggu) dan 2 kali pada trimester III (29 sampai 36 minggu).

Teori oleh Dewi (2011) tujuan kunjungan kehamilan yaitu memantau kemajuan kehamilan untuk memastikan kesehatan ibu dan tumbuh kembang bayinya, mempersiapkan peran ibu dan keluarga dalam menerima kelahiran bayi agar dapat tumbuh normal, mempersiapkan ibu menghadapi masa nifas secara normal dan pemberian ASI eksklusif, menganalisa secara dini adanya ketidaknormalan dan komplikasi yang mungkin terjadi selama hamil, meningkatkan dan mempertahankan kesehatan fisik, mental, sosial ibu dan bayi.

Hasil penelitian yang dilakukan oleh Herlinawati tentang "Hubungan Antara Pengetahuan Ibu Hamil Tentang Kehamilan Resiko Tinggi Dengan Kunjungan Antenatal Care Di Puskesmas Sungan Durian Kabupaten Kubu Raya Tahun 2017” bahwa sebagian besar dari responden melakukan kunjungan antenatal care sesuai standar yaitu 22 orang $(73,3 \%)$. Tabulasi silang menunjukkan bahwa dari 19 orang yang berpengetahuan baik sebagian besar responden $(73,3 \%)$ yaitu 14 orang melakukan kunjungan antenatal care sesuai standar.

Sedangkan hasil penelitian yang dilakukan oleh Fitriana dengan judul "Hubungan Tingkat Pengetahuan Ibu Hamil Trimester III Tentang Tanda Bahaya Kehamilan Dengan kepatuhan Melakukan ANC Di BPS Sri Martuti Piyungan" Tahun 2011 bahwa melaksanakan kunjungan ANC secara patuh $(77,4 \%)$.

Terdapat juga hasil peneliti berdasarkan observasi terhadap kepatuhan kunjungan kehamilan pada buku KIA responden diketahui bahwa sebagian besar dari responden yaitu 35 responden $(70 \%)$ tidak patuh dalam melakukan kunjungan kehamilan sesuai standar, dan sebagian kecil dari responden yaitu 30 responden $(30 \%)$ patuh dalam kunjungan kehamilan sesuai standar.

Tindakan yang harus dilakukan untuk ibu hamil yang tidak patuh yaitu memberikan motivasi terhadap ibu untuk melakukan 
kunjungan kehamilan, serta memberikan motivasi ke suami ibu untuk membantu memberikan dukungan kepada ibu agar ibu rutin dalam melakukan kunjungan kehamilan.

\section{Hubungan Antara Pengetahuan Ibu Hamil} tentang Tanda Bahaya Kehamilan dengan kepatuhan Kunjungan Kehamilan

Berdasarkan tabel 3 tabulasi silang menunjukkan bahwa sebagian besar dari responden yaitu 30 responden yang memiliki pengetahuan kurang (60\%) yaitu 28 responden yang tidak patuh dalam kunjungan kehamilan sesuai standar $(56 \%)$ dan sangat sedikit dari responden yaitu 2 responden yang patuh (4\%).

Telah dilakukan perhitungan dengan rumus chi kuadrat didapatkan nilai hitung $X^{2}$ hitung sebesar 37,47 sedangkan nilai pada tabel chi square $\mathrm{Db} 2$ dengan tingkat kepercayaan 95\% dan tingkat kesalahan 5\%. Pada penelitian ini $X^{2}$ hitung $(37,47) \geq \mathrm{x}$ tabel $(5,991)$ yang artinya Ha diterima dan Ho ditolak artinya Ada Hubungan antara pengetahuan ibu hamil tentang tanda bahaya kehamilan dengan kepatuhan kunjungan kehamilan.

Menurut teori oleh Susanti (2013) kepatuhan melakukan kunjungan kehamilan didefinisikan perilaku ibu hamil yang mentaati semua anjuran oleh petugas kesehatan dalam melakukan kunjungan kehamilan. Kepatuhan kunjungan kehamilan diperoleh melalui perhitungan kunjungan kehamilan. Ibu hamil dikategorikan patuh apabila ibu hamil melakukan kunjungan kehamilan minimal 1 kali pada trimester I (0 sampai 12 minggu), 1 kali pada trimester II (13 sampai 28 minggu) dan 2 kali pada trimester III (29 sampai 36 minggu) sebaliknya ibu hamil dikatakan tidak patuh apabila ibu tidak melakukan kunjungan kehamilan minimal 1 kali pada trimester I (0 sampai 12 minggu), 1 kali pada trimester II (13 sampai 28 minggu) dan 2 kali pada trimester III (29 sampai 36 minggu).

Pengetahuan tanda bahaya kehamilan dan kepatuhan kunjungan kehamilan didapatkan hasil bahwa sebagian kecil dari responden yang memiliki pengetahuan baik dan patuh yaitu 11 responden (22\%), tidak patuh 0 respoden, dan sangat sedikit dari responden yang memiliki pengetahuan kurang dan patuh yaitu 2 responden $(4 \%)$ dan sebagian besar responden tidak patuh yaitu 28 responden $(56 \%)$.

Hal ini sesuai dengan penelitian yang dilakukan oleh Fitriana dengan judul "Hubungan Tingkat Pengetahuan Ibu Hamil Trimester III Tentang Tanda Bahaya Kehamilan Dengan kepatuhan Melakukan ANC Di BPS Sri Martuti Piyungan" Tahun 2011, bahwa ibu hamil di BPS Sri Martuti Piyungan sebagian besar memiliki pengetahuan tentang tanda bahaya kehamilan tinggi (51,6\%) dengan tingkat pendidikan sebagian besar SLTA $(61,3)$, melaksanakan kunjungan ANC secara patuh $(77,4 \%)$.

Pengetahuan ibu hamil sangat berpengaruh dalam melakukan kunjungan kehamilan, dimana semakin baik pengetahuan ibu hamil tentang tanda bahaya kehamilan maka semakin patuh pula dalam melakukan kunjungan kehamilan, dan apabila pengetahuan ibu hamil kurang tentang tanda bahaya 
kehamilan maka semakin tidak patuh dalam melakukan kunjungan kehamilan.

\section{Kesimpulan}

Ada hubungan antara pengetahuan ibu hamil tentang tanda bahaya kehamilan dengan kepatuhan kunjungan kehamilan, yaitu dengan hasil $X^{2}$ hitung $(37,47) \geq \mathrm{x}$ tabel $(5,991)$. Saran bagi petugas kesehatan untuk memberikan informasi tentang tanda-tanda bahaya kehamilan.

\section{Daftar Pustaka}

Asrinah, Putri, dkk. 2010. Asuhan Kebidanan Masa Kehamilan. Yogyakarta: GRAHA ILMU

Astuti Puji, Hutari. 2012. Buku Ajar Asuhan Kebidanan Ibu I (Kehamilan). Yogyakarta: Rohitma Press

Fitriana, 2011. Hubungan Tingkat Pengetahuan Ibu Hamil Trimester III Tentang Tanda Bahaya Kehamilan Dengan Kepatuhan Melakukan ANC di BPS Sri Martuti Piyungan. karya Tulis Ilmiah. Sekolah Tinggi Ilmu Kesehatan Jenderal Achmad Yani Yogyakarta

Hani, Ummi, Kusbandiyah, dkk. 2010. Asuhan kebidanan pada Kehamilan Fisiologis. Jakarta: Salemba Medika

Herlinawati, Mila. 2017. Hubungan Antara Pengetahuan Ibu Hamil Tentang Kehamilan Resiko Tinggi Dengan Kunjungan Antenatal Care di Puskesmas Sungai Durian Kabupaten Kubu Raya. Akademi Kebidanan Panca Bhakti Pontianak (tidak dipublikasikan)

Indrayani. 2011. Buku Ajar Asuhan Kehamilan. Jakarta Timur: CV. Trans Info Media
Indriyani, Diyan. 2013. Keperawatan Maternitas. Yogyakarta: Graha Ilmu

Kementrian Kesehatan Republik Indonesia. 2016. Faktor Utama Penyebab Kematian Ibu.

http://www.depkes.go.id/resources/down load/pusdatin/infodatin/infodatinibu.pdf. Diakses:18 Maret 2019, 12.10 WIB

Kuswanti, Ina. 2014. Asuhan Kehamilan. Yogyakarta: Pustaka Pelajar

Lockhart RN, Anita \& Saputra, Lyndon. 2014. Asuhan Kebidanan Kehamilan Fisiologis \& Patologis. Tangerang Selatan: BINARUPA AKSARA Publisher

Marmi 2011. Asuhan kebidanan Pada Masa Antenatal. Yogyakarta: Pustaka pelajar

Munawaroh, Ismiyatun. 2017. Gambaran Kepatuhan Ibu Hamil Dalam Antenatal Care (ANC) di Wilayah Kerja Puskesmas Kokap I. Website: repository.unjaya.ac.id

Notoatmodjo, Soekidjo. 2010. Promosi Kesehatan Teori dan Aplikasinya. Jakarta: Rineka Cipta

2012. Metodologi Penelitian kesehatan. Jakarta: Rineka Cipta

Pantikawati, Ika. 2010. Asuhan Kebidanan I. Yogyakarta: Nuha Medika

Profil Kesehatan Provinsi Kalimantan Barat. 2017. Angka Kematian Ibu (AKI) di Kalimantan Barat. https://dinkes.kalbarprov.go.id/wpcontent/uploads/2018/08/profilkesehatan-prov-kalbar-th-2017.pdf. Diakses: 4 maret 2019, 10.35 WIB.

Pudiastuti Dewi, Ratna. 2011. Asuhan Kebidanan Pada Hamil Normal, Patologi. Yogyakarta: Nuha Medika 


\begin{tabular}{l}
\hline \\
\hline $\begin{array}{l}\text { Kebidanan Komunitas. Yogyakarta: Nuha } \\
\text { Medika }\end{array}$ \\
Sari, Anggrita, Ulfa, dkk. 2011. Buku Asuhan \\
kebidanan Pada Kehamilan: Untuk \\
Mahasiswa Kebidanan. Bogor: Penerbit \\
IN MEDIA
\end{tabular}

Setyawan, Ari \& Saryono. 2011. Metodologi Penelitian Kebidanan DIII, DIV, S1 dan S2. Yogyakarta: Nuha Medika

Sukarni, Icesmi \& Sudarti. 2014. PATOLOGI: Kehamilan, Persalinan, Nifas dan Neonatus Resiko Tinggi. Yogyakarta: Nuha Medika

Sulistyawati, Ari. 2009. Asuhan Kebidanan Pada Masa Kehamilan. Jakarta: Salemba Medika

Susila \& Suyanto. 2014. Metodologi Penelitian Cross sectional. Klaten: BOSSSCRIPT

Syafrudin, dkk. 2009. Kebidanan Komunitas. Jakarta: Katalog Dalam Terbitan (KDT)

Walyani, Siwi Elisabeth, dkk. Konsep dan Asuhan Kebidanan Maternal dan Neonatal. Yogyakarta: PUSTAKABARUPRESS

Waryana. 2016. Promosi Kesehatan, Penyuluhan dan Pemberdayaan Masyarakat. Yogyakarta: Nuha medika

WHO. 2013. Buku Saku Kesehatan Ibu di Fasilitas Kesehatan Dasar dan Rujukan, Indonesia: WHO 